oxalate, phosphate, ammonium, magnesium, or carbonate-that is, the composition did not differ from that of stones found in a population denying the consumption of analgesics.

It may be argued that as we have accepted renal colic and radiotranslucent material in the urinary passages as criteria for urinary stone formation, a number of patients may have been included whose renal colic and radiological appearances were due to necrotic papillae (Lindholm, 1960). However, all female patients in the "heavy" analgesic group had radiological evidence of calcified material in the urinary tract. While papillary debris may have been initially responsible for the calcification, this does not seem to us a good reason for not calling this material a "stone."

\section{Summary}

Forty-five of a series of 266 patients with renal calculi gave a history of heavy consumption of analgesics. A mechanism is suggested for the association between the two conditions.

Prolonged consumption of analgesics with calcification of necrotic papillary material should be included among the causes of renal calculi.

Drs. F. C. Neale, F. Jennis, and J. T. Wright are hereby thanked for their help in the investigation of these patients.

This study was supported by the Postgraduate Medical Foundation, the University of Sydney, the N.S.W. State Cancer Council, and the Edanros Research Foundation Inc., New York.
REFERENCES

Boyce, W. H., and Bradshaw, H. H. (1961). F. Urol. (Baltimore), 85, 223. - and King, J. S. (1963). Ann. N.Y. Acad. Sci., 104, 563.

Burry, A. F., de Jersey, P., and Weedon, D. (1966). Med. F. Aust., 1, 873.

Dawborn, J. K., Fairley, K. F., Kincaid-Smith, P., and King, W. E. (1966). Quart. F. Med., 35, 69.

Kincaid-Smith, P., and McLaren, J. (1964). Aust. Ann. Med., 13, 217.

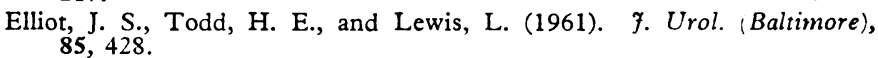

Fordham, C. C., Huffines, W. D., and Welt, L. G. (1965). Ann. intern. Med., 62, 738 .

Gilman, A. (1964). Amer. F. Med., 36, 167.

Hodgkinson, A., and Pyrah, L. N. (1958). Brit. F. Surg., 46, 10.

Howard, J. E., Thomas, W. C., Mukai, T., Johnston, R. A., and Pascoe, B. J. (1962). Trans. Ass. Amer. Phycns, 75, 301.

Hultengren, N. (1961). Acta chir. scand., Suppl. No. 277, p. 62.

Jacobs, L. A., and Morris, J. G. (1962). Med. F. Aust., 2, 531.

Lancet, 1966, 2, 1451.

Larsen, K., and Møller, C. E. (1959). Acta med. scand., 164, 53.

Lavan, J. N., Benson, W. J., Gatenby, A. H., and Posen, S. (1966). Med. F. Aust., 2, 694.

Lindeneg, O., Fischer, S., Pedersen, J., and Nissen, N. I. (1959). Acta med. scand., 165, 321 .

Lindholm. T. (1960). Ibid., 167, 319.

Maurice, P. F., and Henneman, P. H. (1961). Medicine (Baltimore), 40, 315.

Melick, R. A., and Henneman, P. H. (1958). New Engl. F. Med., 259, 307.

Metcalfe-Gibson, A., McCallum, F. M., Morrison, R. B. I., and Wrong, O. (1965). Clin. Sci., 28, 325 .

Nordin, B. E. C., and Robertson, W. G. (1966). Brit. med. F., 1, 450.

Rubenstein, A. H., Abrahams, C., Stables, D. P., and Levin, N. W. (1964). Arch. intern. Med., 113, 378.

Brit. med. F., 1967, 2, 802-804

When Lyell (1956) first described toxic epidermal necrolysis few reports of cases showing any similarity to the disease had appeared. Subsequent series described only a few cases ; but, nevertheless, these reports indicate that the disease has a widespread distribution, that it is not uncommon, and that it is important to recognize it-since the average fatality rate has been at least $20 \%$.

Since Lyell's original description-which has not been bettered-little has been added to descriptions of the clinical or histological features of the condition. In particular I have found his subtitle of "An eruption resembling scalding of the skin" most apt, especially his emphasis on the absence of exudation and shock. Many observers have suggested a drug reaction in the aetiology of the condition, especially in adults, though infection has also been implicated by others (Beare, 1962). Holzel and Jacobs (1966) and Tyson et al. (1966) have suggested that haemolytic staphylococci may be concerned, and my own findings support this view.

\section{Patients Studied}

Between 1956 and 196731 children have been seen with the features of Lyell's toxic epidermal necrolysis (see Table). Some of the characteristics of the condition are discussed below.

\section{Clinical Course}

The disease starts as a localized lesion, followed by a sudden, widespread erythema and exfoliation of the skin with a period of critical illness lasting for some two to seven days. This is succeeded by a dramatic change in which the tenderness disappears, temperature subsides, and the patient is no longer ill. This moment is unmistakable and is highly reminiscent of the crisis previously associated with pneumonia.

All 31 cases occurred before the age of 10 ; of the 13 affected in the first year of life, seven were aged 4 weeks or under, the youngest patient developing the disease some 48 hours after birth. The disease was fatal in a 3-day-old child, though six other neonates made a complete recovey and some of the most severe cases were seen in the older children.

Of the total of 31 patients 18 were boys-while of the 13 patients under 1 year old nine were boys.

Complications were uncommon and included moderate respiratory infections (6 cases), dysuria (2 cases), delirium and muscle twitching ( 1 case). In this series there were no recurrences, and, though some of the earlier cases developed candida infection, it was found possible to eliminate them by appropriate nystatin cover.

\section{Drugs}

Only five children were found to have received drugs recently, before the onset of the condition. For example, one child (Case 1) was already suffering from juvenile dermatitis herpetiformis and had been treated with sulphamethoxypyridazine (Lederkyn) for over a year with good control of her rash. On admission, she was ill and $80 \%$ of her skin was affected by

* Consultant Dermatologist, Belfast City Hospital, Belfast 9. 
classical Lyell's disease-though this was diagnosed only in retrospect. In view of reports that long-acting sulphonamides may produce this condition, it is important to record that treatment was later resumed without recurrence or any toxic effect.

\section{Infection}

The Table shows that staphylococci were isolated in all but four instances. Originally this organism had been regarded as a secondary invader, and it seemed unlikely that it would be producing a new syndrome. Nevertheless, this possibility was considered when a series of cases was seen which clearly could not have been due to drugs. Thus Cases 4, 5, and 6 occurred simultaneously and involved a twin brother and sister and an older brother. Study of the course of the illness in cases seen subsequently suggested an infective aetiology, and all patients were treated with systemic and local antibiotics. A localized skin focus was usually detectable clinically and could be confirmed by history. This focus was followed by extensive erythema and superficial exfoliation resembling scalding. In some cases, seen when the condition was fully established, no distinctive primary focus could be recognized; this, however, was not surprising, because the original area was noted to assume the classical denuded scalded appearance.

One patient (Case 24) was seen at a very early stage.

Case 24.-A girl aged 4 years had been off-colour for two days, had a mild pyrexia, stinging in the eyes/general irritability, and a rash surrounding the mouth. The rash was confluent, very moist, erythematous, and covered in yellow crusts. The rest of the skin was normal apart from minimal pinkness on the chest, and mucous membranes were clear, though there was conjunctival infection. Some eight hours later the child showed all the features of the "scalded skin syndrome" with almost $75 \%$ skin involvement.

Routine periodic phage-typing showed that all the staphylococci found in these cases belonged to group 71. The original lesions on the limbs presented as bullous impetigo, while those on the trunk or face presented as confluent impetigo. Nevertheless, unlike the usual case of impetigo, the latter did not spread in a patchy manner, but were restricted to one or two fairly sizable areas. On the face these tended to be situated around the mouth, nostrils, or eyes. From 10 cultures out of 13 swabs taken from these primary areas Staphylococcus aureus phage type 71 was isolated, while the three cases which were sterile had been treated with local antibiotic before admission.
On the other hand, swabs from the " scalded" areas were almost invariably sterile-a finding which suggested that such lesions. were not caused directly by staphylococci. Virological studies also gave negative results.

Blood counts performed in eight patients were normal in six, and showed moderate leucocytosis in two. Blood culture in six cases was negative. At necropsy in the single fatal case there were remarkably few abnormalities, this showing-apart from the extensive superficial skin exfoliation-only mild congestive and toxic changes in the lungs, liver, and kidney.

\section{Treatment}

Systemic corticosteroid drugs, in addition to other therapy including antibiotics, were given in four cases, but did not seem to produce any particular improvement. I suggest that it would seem wiser not to use the drug. The following measures seem likely to produce the best results:

1. Isolation and Strict Barrier Nursing.

2. Skilled and Devoted Nursing Care.-The tenderness in the skin is extreme and presents a great challenge; these children are uncomfortable, irritable, ill, and fearful of every approach.

3. Adequate Fluid Intake.-Though administration of fluids is often difficult, an adequate intake must be maintained, and this was achieved by oral administration in every case.

4. Systemic Antibiotics.-These should be given in full dosage for age. In severe cases two drugs were administered until laboratory guidance was available.

5. Local Antibiotics.-Most applications were found to be suitable, being applied frequently to all raw areas, whether infected or not. Treatment of carrier sites should be done as a routine and may be important in preventing recurrence.

6. Oral Nystatin.-Appropriate cover with this was found to prevent candida infection.

7. Sedation.- This was found to be a valuable measure, and in younger patients antihistamines were usually adequate.

\section{Discussion}

Most cases of Lyell's toxic epidermal necrolysis due to drugs have been described in adults (Browne and Ridge, 1961), and it is difficult to doubt this association-especially when readministration has been shown to produce recurrence. Thus Lyell's (1956) original four cases were adults, a drug origin being con-

\begin{tabular}{|c|c|c|c|c|c|c|c|c|c|c|c|c|c|}
\hline \multirow{2}{*}{$\begin{array}{l}\text { Case } \\
\text { No. }\end{array}$} & \multirow[b]{2}{*}{ Year } & \multirow[b]{2}{*}{ Sex } & \multirow[b]{2}{*}{ Age } & \multirow[b]{2}{*}{ Site of Onset } & \multicolumn{2}{|c|}{ Maximum Temp. } & \multirow{2}{*}{$\begin{array}{c}\text { Drugs } \\
\text { taken before } \\
\text { Onset of Illness }\end{array}$} & \multicolumn{6}{|c|}{ Culture Results } \\
\hline & & & & & ${ }^{\circ} \mathrm{F}$. & ${ }^{\circ} \mathrm{C}$. & & $\begin{array}{c}\text { Primary } \\
\text { Skin }\end{array}$ & Eyes & Throat & Nostril & Ears & $\begin{array}{l}\text { Per1- } \\
\text { neum }\end{array}$ \\
\hline $\begin{array}{r}1 \\
2 \\
3 \\
4 \\
5 \\
6 \\
7 \\
8 \\
9 \\
10 \\
11 \\
12 \\
13 \\
14 \\
15 \\
16 \\
17 \\
18 \\
19 \\
20 \\
21 \\
22 \\
23 \\
24 \\
25 \\
26 \\
27 \\
28 \\
29 \\
30 \\
31\end{array}$ & $\begin{array}{l}1956 \\
1957 \\
1958 \\
1958 \\
1958 \\
1958 \\
1958 \\
1958 \\
1958 \\
1958 \\
1959 \\
1959 \\
1959 \\
1960 \\
1960 \\
1961 \\
1961 \\
1962 \\
1962 \\
1962 \\
1963 \\
1963 \\
1963 \\
1963 \\
1964 \\
1964 \\
1965 \\
1966 \\
1966 \\
1966 \\
1967\end{array}$ & $\begin{array}{l}\mathrm{F} \\
\mathrm{F} \\
\mathrm{F} \\
\mathrm{F} \\
\mathrm{M} \\
\mathrm{M} \\
\mathrm{M} \\
\mathrm{M} \\
\mathrm{M} \\
\mathrm{M} \\
\mathrm{M} \\
\mathrm{F} \\
\mathrm{F} \\
\mathrm{M} \\
\mathrm{M} \\
\mathrm{M} \\
\mathrm{M} \\
\mathrm{M} \\
\mathrm{M} \\
\mathrm{F} \\
\mathrm{F} \\
\mathrm{M} \\
\mathrm{M} \\
\mathrm{F} \\
\mathrm{M} \\
\mathrm{M} \\
\mathrm{M} \\
\mathrm{F} \\
\mathrm{F} \\
\mathrm{F} \\
\mathrm{F}\end{array}$ & 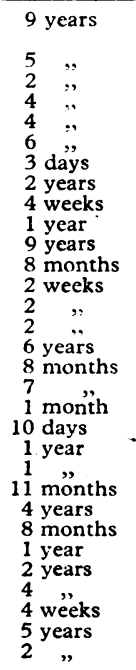 & $\begin{array}{l}\text { Face } \\
\text { Shoulder } \\
\text { Upper trunk } \\
\text { Face } \\
\text { Legs } \\
\text { Face } \\
\text { Umbilicus } \\
\text { Leg } \\
\text { Ear } \\
\text { Leg } \\
\text { Face } \\
\text { Hand } \\
\text { Face } \\
. . \\
\ddot{~} \\
. \\
. \\
. \\
. \\
. \\
\ddot{~} \\
\text { Abdomen } \\
\text { Chest } \\
\text { Face } \\
\text { " } \\
\text { ". } \\
\text { ". }\end{array}$ & $\begin{array}{r}103 \cdot 8 \\
99 \cdot 8 \\
100 \cdot 2 \\
100 \cdot 4 \\
99 \cdot 4 \\
100 \cdot 4 \\
98 \cdot 0 \\
101 \cdot 8 \\
100 \cdot 4 \\
101 \cdot 8 \\
99 \cdot 0 \\
99 \cdot 0 \\
100 \cdot 0 \\
99.4 \\
99 \cdot 4 \\
102 \cdot 0 \\
100 \cdot 0 \\
100 \cdot 4 \\
99 \cdot 8 \\
100 \cdot 0 \\
101 \cdot 6 \\
100 \cdot 0 \\
101 \cdot 2 \\
100 \cdot 0 \\
104 \cdot 4 \\
104 \cdot 2 \\
102 \cdot 4 \\
101 \cdot 4 \\
101 \cdot 0 \\
100 \cdot 0 \\
100 \cdot 8\end{array}$ & $\begin{array}{l}39 \cdot 9 \\
37 \cdot 7 \\
37 \cdot 9 \\
38 \cdot 0 \\
37 \cdot 4 \\
38 \cdot 0 \\
36 \cdot 7 \\
38 \cdot 8 \\
38 \cdot 0 \\
38 \cdot 8 \\
37 \cdot 2 \\
37 \cdot 2 \\
37 \cdot 8 \\
37 \cdot 4 \\
37 \cdot 4 \\
38 \cdot 9 \\
37 \cdot 8 \\
38 \cdot 0 \\
37 \cdot 7 \\
37 \cdot 8 \\
38 \cdot 7 \\
37 \cdot 8 \\
38 \cdot 4 \\
37 \cdot 8 \\
40 \cdot 2 \\
40 \cdot 1 \\
39 \cdot 1 \\
38 \cdot 6 \\
38 \cdot 3 \\
37 \cdot 3 \\
38 \cdot 2\end{array}$ & $\begin{array}{l}\text { Tetracycline } \\
\text { Triple vaccine }\end{array}$ & $\begin{array}{l}S \\
S \\
S \\
S \\
S \\
S \\
S \\
S \\
S \\
S \\
71 \\
- \\
55 / 71 \\
S \\
71 \\
71 \\
S \\
71 \\
71 \\
S \\
71 \\
71 \\
71\end{array}$ & $\begin{array}{l}\overline{-} \\
55 / 71 \\
\overline{71} \\
71 \\
\frac{5}{71} \\
\overline{71} \\
\frac{71}{4}\end{array}$ & $\begin{array}{l}\bar{z} \\
55 / 71 \\
\bar{s} \\
\bar{z} \\
\overline{71}\end{array}$ & $\begin{array}{c}- \\
\mathrm{s} \\
\overline{71} \\
55 / 71 \\
\overline{71} \\
\overline{71} \\
\overline{71} \\
\overline{71}\end{array}$ & $\begin{array}{l}- \\
- \\
\frac{71}{71}\end{array}$ & $\begin{array}{l}71 \\
71 \\
\overline{71} \\
\overline{-} \\
\overline{71} \\
71\end{array}$ \\
\hline
\end{tabular}


sidered likely in one case and possible in another. Nevertheless, it seems strange that such a specific disease pattern should suddenly be produced by the many different drugs recorded. As more reports appear, moreover, the incidence of cases due to drugs seems to diminish. In the present series of casesthe largest yet reported-it seems clear that the disease was not a septicaemia. On the contrary, my findings suggest that it is caused by phage-type-71 Staph. aureus, which produces a local skin condition, together with a secondary toxaemia, comparable to that produced by the streptococcus in scarlet fever. Possibly the staphylococcus produces an altered, potentiated, or new toxin, which in a non-immune person gives rise to toxic epidermal necrolysis. Though a search for rashes in other members of the household has not been made routinely, four cases were associated with impetigo, and, recently, routine nasal swabbing revealed phage type 71 in one parent in three different cases. Furthermore, the simultaneous involvement of two brothers and a sister, and the high incidence in children, would suggest an infection in those without resistance. Again, the geographical incidence supports infection, and a small region like Northern Ireland, with a population of under $1,000,000$, has a relatively large number of cases, since $41+$ have now been published and the number is undoubtedly higher.

\section{Summary}

Thirty-one cases of Lyell's toxic epidermal necrolysis are described. It is suggested that the condition starts as a local skin infection, followed by an extensive erythema and superficial exfoliation resembling scalding. This critical period of illness

t Ten reported by Beare (1962). is succeeded by the sudden onset of recovery, reminiscent of the crisis course formerly seen in cases of pneumonia.

Death occurred in a 3-day-old infant, but all other patients recovered completely without recurrence.

The primary skin lesion was found to be caused by phagetype-71 Staphylococcus aureus, and it is postulated that the "scalded skin syndrome" is due to a unique toxic effect of this organism. Thus, while a drug or other cause may be considered, a search for this organism is indicated in all cases.

Treatment consists of skilled nursing together with the administration of antibiotics, systemic and topical ; corticosteroid drugs are not indicated.

I am grateful to Dr. C. Field (consultant paediatrician) for inviting me to see several cases under his care, and for referring some cases to my unit. I am also indebted to Dr. F. F. Kane (consultant physician, Northern Ireland Fever Hospital) for allowing me to have details of Cases 4, 5, and 6. My thanks are also due to Mrs. Landau (senior scientific officer of the hospital laboratory) for her enthusiastic co-operation regarding bacteriology and phagetyping in these cases. Since results are largely dependent on skilled and devoted nursing, I am particularly grateful to the nursing staff, and especially to Sister Adams and Staff Nurse Burton. Finally, I am greatly indebted to my senior secretary, Mrs. McKnight.

\section{REFERENCES}

Beare, M. (1962). Arch. Derm., 86, 638.

Browne, S. G, and Ridge, E. (1961). Brit. med. F., $1,550$.

Holzel, A., and Jacobs, S. I. (1966). Schweiz. med. W schr., 96, 427.

Lyell, A. (1956). Brit. f. Derm., 68, 355.

Tyson, R. G., Ushinski, S. C., and Kisilevsky, R. (1966). Amer. F. Dis. Child., 111, 386.

\title{
Laboratory and Pharmacological Studies in Man with Hetacillin and Ampicillin
}

\author{
R. SUTHERLAND,* B.SC. ; O. P. W. ROBINSON,* M.B., B.S.
}

Brit. med. 7., 1967, 2, 804-808

Hetacillin is the generic name for 6-(2,2-dimethyl-5-oxo-4phenyl-1-imidazolidinyl)penicillanic acid, which is prepared by the reaction of ampicillin with acetone (Hardcastle et al., 1966) (Fig. 1). The antibacterial spectrum of hetacillin has not been reported in detail, but Bunn et al. (1966) have stated that hetacillin has essentially the same spectrum of activity in vitro as ampicillin. Absorption and excretion studies with hetacillin in man have been reported by Bunn et al. (1966) and by Tuano et al. (1966). The results of clinical trials with hetacillin were reported at the Sixth Interscience Conference on Antimicrobial

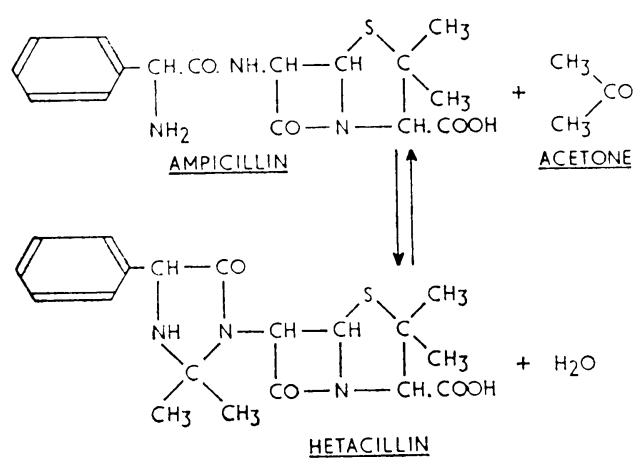

Fig. 1.-Structure of hetacillin.
Agents and Chemotherapy (Philadelphia, U.S.A., 1966-proceedings in press).

The experiments reported here were designed to investigate the hydrolysis of hetacillin to ampicillin in vitro and in man, and to compare the antibacterial activities, and the absorption and excretion in man, of hetacillin and ampicillin.

\section{Hydrolysis of Hetacillin to Ampicillin}

In aqueous solution hetacillin hydrolyses to form ampicillin and acetone. The formation of ampicillin was demonstrated by thin-layer chromatography as described by Hardcastle $e t$ al. (1966). The formation of acetone was demonstrated by gas chromatography. Fig. 2 shows the rate of hydrolysis of hetacillin to ampicillin at $37^{\circ} \mathrm{C}$. in aqueous solution at $\mathrm{pH} 7$. Under these conditions hydrolysis of hetacillin was rapid, so that within 15 minutes at $37^{\circ} \mathrm{C}$. more than $50 \%$ of an aqueous solution of $1 \mathrm{mg}$. of hetacillin per $\mathrm{ml}$. in $\mathrm{M} / 40$ phosphate buffer, $\mathrm{pH} \mathrm{7,} \mathrm{had} \mathrm{hydrolysed} \mathrm{to} \mathrm{ampicillin,} \mathrm{and} \mathrm{at} \mathrm{the} \mathrm{end} \mathrm{of}$ 60 minutes there was virtually no unchanged hetacillin in solution. The rate of hydrolysis under acid conditions $(p \mathrm{H} \mathrm{2})$ was less rapid, but after 60 minutes there was about $50 \%$ conversion of hetacillin to ampicillin. 